\title{
Characterization and Antimicrobial Susceptibility Pattern of Clinical Isolates of Enterococci in a Tertiary Care Cancer Hospital, Kerala, India
}

\author{
Swapna Raveendranath*, Remya Nair and Sagila Savithri Gangadharan
}

Division of Microbiology, Regional Cancer Centre, Thiruvananthapuram, 695 011, India

*Corresponding author

\section{A B S T R A C T}

\section{Keywords}

Enterococcal species,

Vancomycin resistance, Infection control.

Article Info

Accepted:

18 January 2017

Available Online:

10 February 2017
Enterococci have emerged as an increasingly important cause of nosocomial infections in patients with cancer. The emergence of vancomycin-resistant enterococci (VRE) is a cause of concern, as once established, it is very difficult to control. A study on the characterization and antimicrobial susceptibility pattern of clinical isolates of enterococci from patients with cancer was carried out in the Division of Microbiology, Regional Cancer Centre, Thiruvananthapuram for a period of three months. A total of 100 enterococcal isolates obtained from various clinical samples were included in the study. E. faecium (73\%) was the predominant enterococcal species isolated in the study followed by $E$. faecalis (24\%) and E. durans (3\%). $18 \%$ of the enterococcal strains were resistant to vancomycin with an MIC ranging from $32 \mu \mathrm{g} / \mathrm{ml}$ to $512 \mu \mathrm{g} / \mathrm{ml}$. All strains were susceptible to linezolid and tigecycline. Vancomycin resistance was observed in a significant percentage of enterococcal isolates. Tigecycline or linezolid should be considered in empirical treatment of presumed enterococcal sepsis. Stringent infection replace "prevention" with control measures and restricted use of vancomycin are important measures to reduce the emergence of resistant enterococci.

\section{Introduction}

Enterococci, morphologically resembling Streptococci, are gram positive facultative anaerobic cocci with ability to grow in extreme conditions. They form a part of the normal flora of intestinal tract, oral cavity, and vagina, but they have emerged as important nosocomial pathogens. Enterococcus faecalis and Enterococcus faecium are the most prevalent species in humans accounting for more than $90 \%$ of clinical isolates (Sreeja et al., 2012). Enterococci are capable of causing both endogenous and exogenous infections.
Infections commonly caused by enterococci include urinary tract infections, bacteremia, endocarditis, catheter-related infections, wound and soft tissue infections, meningitis, respiratory infections, neonatal sepsis and intra-abdominal and pelvic infections. Even though considered as low grade pathogens, they are becoming of great concern because of emergence of drug resistant strains (Intrinsic and acquired drug resistance). They are intrinsically resistant to penicillinasesusceptible penicillin (low level), penicillinase-resistant penicillins, cephalo 
sporins, nalidixic acid, aztreonam, macrolides, and low levels of clindamycin and aminoglycosides. Enterococci also have acquired resistance, which includes resistance to penicillin by beta-lactamases, chloramphenicol, tetracyclines, rifampin, fluoroquinolones, aminoglycosides (high levels), and vancomycin (Mandell et al., 2005). Vancomycin resistance has seriously affected the treatment and infection control of these organisms. Vancomycin resistant enterococci (VRE), particularly E. faecium strains, are frequently resistant to all antibiotics that are effective for treatment of vancomycin-susceptible enterococci, which leaves clinicians treating VRE infections with limited therapeutic options.

Enterococcal bacteremia was considered as a rare infection associated with malignancy and was attributed to the mucosal damage from chemotherapeutic agents (Venditti et al., 1993). The advent of VRE has changed this paradigm. VRE is associated with high prevalence of bacteremia and invasive infections in bone marrow transplant recipients. Patients with other malignancies also have high risk of VRE infections (Zaas et al., 2002). Therapeautic and prophylactic use of vancomycin is a major risk factor for both VRE gastrointestinal colonization and bacteremia in patients with cancer. Risk factors for acquiring nosocomial enterococcal infections include gastro intestinal colonization, gastrointestinal surgery, neutropenia and presence of urinary or vascular catheters.

On this background we sought to study the prevalence of enterococcal infection and the antibiogram in patients with underlying malignancy in a tertiary care cancer hospital.

The main aim of this study to characterize and determine the antimicrobial susceptibility pattern of isolates of enterococci obtained from various clinical samples in Microbiology division, Regional Cancer Centre, Thiruvananthapuram, Kerala.

\section{Materials and Methods}

Consecutive enterococcal isolates obtained during a period of three months from April 2016 to June 2016 were speciated and analyzed for antibiotic susceptibility and the incidence and patterns of antibiotic resistance were assessed.

\section{Isolation and identification of Enterococci}

Clinical specimens received in the Microbiology laboratory including blood samples, pus aspirates, stool samples, throat swabs, pus swabs and urine samples were processed as per the standard protocols. Specimens were inoculated on to solid media such as Blood agar, Mac conkey agar, Tellurite blood agar and also to liquid broth. All media were incubated at $37^{\circ} \mathrm{C}$.

After 24 hrs of incubation, growth was observed on solid media. Growth of enterococci on solid media were as follows: On blood agar plate, enterococci produced small, round, smooth, transparent colonies and some colonies showed hemolysis alpha $(\alpha)$ or $\operatorname{beta}(\beta)$ and some were non-hemolytic. On Mac conkey's medium entercococci produced tiny deep pink colonies. On tellurite medium, tolerance to tellurite was determined by production of black colonies on the surface of agar medium containing $0.1 \%$ potassium tellurite. Gram staining was done on the colonies which morphologically resembled enterococci which showed gram positive cocci which were spherical, arranged mostly in pairs or in short chains. Catalase test was performed which was negative. Definitive identification of enterococci was based on bile esculin test, heat tolerance test, survival at $60^{\circ} \mathrm{C}$ for 30 minutes, ability to grow in $6.5 \% \mathrm{NaCl}$ and 
sugar fermentation test. Bile esculin hydrolysis test was positive as indicated by a blackening of media around the colonies. Enterococci also had the ability to grow in $6.5 \% \mathrm{NaCl}$ and tolerated heat at $60^{\circ} \mathrm{C}$ for 30 minutes.

\section{Speciation of enterococci}

The enterococcal isolates thus obtained were then speciated based on Facklams conventional method (Facklam et al., 1989). Speciation was done based on the results obtained in carbohydrate fermentation tests performed in brain heart infusion broth base with $1 \%$ mannitol, sorbitol, raffinose, arabinose, lactose, sucrose, and glucose. Carbohydrate tests produced a yellow colour (due to acid formation) for a positive test and a red or red-orange color for a negative test on adding phenol red indicator. E.faecium fermented raffinose, arabinose, lactose, sorbitol, sucrose, dextrose and mannitol. E.faecalis fermented lactose, manitol, sucrose, dextrose but failed to ferment raffinose, arabinose, sorbitol. E.duransfermented sorbitol, dextrose andmannitol but failed to ferment raffinose, arabinaose, sucrose and lactose (Table 1).

\section{Antimicrobial susceptibility testing}

Antimicrobial susceptibility was done as per Clinical Laboratory Standard Institute (CLSI) guidelines using KirbyBauer disc diffusion method. Minimum inhibitory concentration (MIC) of the antibiotic vancomycin was determined by broth dilution method.

The following antibiotic discs were used for antibiotic susceptibility testing. Penicillin

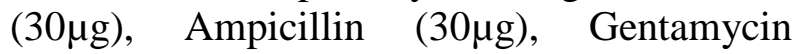

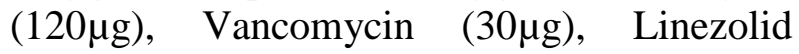
$(30 \mu \mathrm{g}), \quad$ Teicoplanin $(30 \mu \mathrm{g})$, Tigecycline $(30 \mu \mathrm{g}) \quad$ Doxycycline $(30 \mu \mathrm{g})$, Imipenem $(10 \mu \mathrm{g})$, Piperacillin/ tazobactam (),
Meropenem $(10 \mu \mathrm{g}), \quad$ Cefazolin $(10 \mu \mathrm{g})$. Nitrofurantoin $(300 \mu \mathrm{g})$ and Ciprofloxacin $(30$ $\mu \mathrm{g}$ ) were tested only for urine samples.

Vancomycin susceptibility in enterococci was determined by disc diffusion method and confirmed by minimum inhibitory concentration (MIC) method. In disc diffusion method, a zone diameter of $14 \mathrm{~mm}$ or less around vancomycin disc was considered as resistant, and a zone of 15-16 $\mathrm{mm}$ was considered as intermediate and zone size of $\geq$ $17 \mathrm{~mm}$ was considered as sensitive.

In the MIC method, MIC of $\leq 4 \mu \mathrm{g} / \mathrm{ml}$ for vancomycin was considered as sensitive, 8-16 $\mu \mathrm{g} / \mathrm{ml}$ was considered as intermediate and $\geq$ $32 \mu \mathrm{g} / \mathrm{ml}$ was considered as resistant.

\section{Protocol for determining MIC of Vancomycin}

Vancomycin was commercial available in the powder form. Powder was accurately weighed and dissolved in the appropriate diluent to yield the required concentration. The stock solution was aliquoted in $5 \mathrm{ml}$ volume and frozen at $-20^{\circ} \mathrm{C}$.

To get a concentration of $2048 \mu \mathrm{g} / \mathrm{ml}$ of vancomycin, $200 \mathrm{mg}$ of vancomycin was dissolved in $102 \mathrm{ml}$ sterile distilled water which was calculated as per the formula

Volume $(\mathrm{ml})=$

weight of antibiotic $(\mathrm{mg}) \times$ potency $(\mu \mathrm{g} / \mathrm{mg})$ Concentration $(\mu \mathrm{g} / \mathrm{ml})$

Serial dilutions of the stock solution were prepared in sterile test tubes to get a concentration ranging from $2048 \mu \mathrm{g} / \mathrm{ml}$ to 0.5 $\mu \mathrm{g} / \mathrm{ml} \quad(2048 \mu \mathrm{g} / \mathrm{ml}, \quad 1024 \mu \mathrm{g} / \mathrm{ml}, 512 \mu \mathrm{g} / \mathrm{ml}$, $256 \mu \mathrm{g} / \mathrm{ml}, \quad 128 \mu \mathrm{g} / \mathrm{ml}, \quad 64 \mu \mathrm{g} / \mathrm{ml}, \quad 32 \mu \mathrm{g} / \mathrm{ml}$, $16 \mu \mathrm{g} / \mathrm{ml}, 8 \mu \mathrm{g} / \mathrm{ml}, 4 \mu \mathrm{g} / \mathrm{ml}, 2 \mu \mathrm{g} / \mathrm{ml}, 1 \mu \mathrm{g} / \mathrm{ml}$, and $0.5 \mu \mathrm{g} / \mathrm{ml}$ ). Enterococcal colonies were 
inoculated into brain heart infusion broth (BHIB) and turbidity adjusted to 0.5 McFarland standards. $1 \mathrm{ml}$ of BHIB each was added to all test tubes with $1 \mathrm{ml}$ of the required concentration of drug and the test tubes were incubated at $37^{\circ} \mathrm{C}$ for 24 hours.

The tubes were observed for the development of turbidity which indicated bacterial resistance. The lowest concentration of drug which could inhibit the growth of the strain was taken as minimum inhibitory concentration of the drug for the strain (Fig. $1)$.

\section{Results and Discussion}

4710 clinical samples were processed over the period of three months and a total of 100 enterococci isolates were obtained which shows the prevalence of enterococci as $2.1 \%$.

E. faecium $(73 \%)$ was the predominant enterococcal species isolated in the study followed by E. faecalis (24\%). Of the fifty two enterococcal isolates obtained from stool samples, thirty nine $(75 \%)$ were E. faecium and thirteen $(25 \%)$ were E. faecalis. Similarly among twenty three isolates obtained from pus aspirates, sixteen (69.7\%) were E. faecium and six were E. faecalis (26\%) and one isolate was E. durans (4.3\%). Among fifteen urinary isolates, eight $(53.4 \%)$ were E. faecium and five $(33.3 \%)$ were E. faecalis and two (13.3\%) were $E$. durans. Seven isolate obtained from throat swab and three isolate obtained from blood samples were E. faecium (Table 2).

The results of antibiotic susceptibility testing were as follows:

All enterococcal isolates (100\%) were susceptible to linezolid and tigecycline. Vancomycin resistance was noted in $18 \%$ of enterococci. Penicillin and Ampicillin resistance were observed in $85.5 \%$ and $54.2 \%$ of specimens respectively. High level Gentamicin resistance was seen in $65.1 \%$ of the isolates. Table 3 shows the susceptibility profile of enterococcal isolates in the decreasing order of susceptibility.

\section{MIC testing of vancomycin- results}

Out of hundred strains of enterococci obtained from various samples, eighteen strains (18\%) were resistant to vancomycin which included nine strains of E. faecium (50\%), seven strains of E. faecalis (38.9\%) and two strains of $E$. durans $(11.1 \%)$. Those strains which were susceptible to vancomycin had an MIC ranging from $1 \mu \mathrm{g} / \mathrm{ml}$ to $4 \mu \mathrm{g} / \mathrm{ml}$. Resistant strains had an MIC ranging from $32 \mu \mathrm{g} / \mathrm{ml}$ to $512 \mu \mathrm{g} / \mathrm{ml}$.

Three enterococcal isolates (16.7\%) had an MIC of $512 \mu \mathrm{g} / \mathrm{ml}$ followed by seven enterococcal isolates $(38.8 \%)$ with an MIC of $256 \mu \mathrm{g} / \mathrm{ml}$, five isolates (27.7\%) with an MIC of $128 \mu \mathrm{g} / \mathrm{ml}, 2$ isolates (11.1\%) with an MIC of $32 \mu \mathrm{g} / \mathrm{ml}$ and one isolate (5.6\%) with an MIC of $64 \mu \mathrm{g} / \mathrm{ml}$. The enterococcal species which showed a very high MIC of $512 \mu \mathrm{g} / \mathrm{ml}$ was E. faecium, one isolate obtained blood culture and one isolate each from pus aspirate and stool sample. Two isolates of $E$. faecium (2\%) showed moderate susceptibility to vancomycin $(8 \mu \mathrm{g} / \mathrm{ml}$ and $16 \mu \mathrm{g} / \mathrm{ml}$ each) (Table 4).

The emergence of vancomycin resistant enterococci (VRE) is a serious challenge. Multi drug resistant enterococci become the dominant flora under antibiotic pressure, predisposing the severely ill and immunocompromised patient to invasive infections (Miller et al., 2014). In our study, the prevalence of enterococci among various clinical samples was found to be around $2.1 \%$ with $E$. faecium being the commoner isolate. E. faecium is intrinsically more antibioticresistant than $E$. faecalis and treating 
infections with these strains is more difficult. The incidence of present study VRE to be $18 \%$ which is very high compared with published data. As three isolates of E. faecium have shown an MIC of $512 \mu \mathrm{g} / \mathrm{ml}$, high level vancomycin resistance has to be kept in mind while starting the antibiotics empirically in immunosuppressed patients. The vancomycin resistance among enterococcal isolates was $8.7 \%$ in a similar study from south India, published in 2009 (Praharaj et al., 2013).In another observational study from Mumbai, Western India, prevalence of VRE was found to be $23 \%$ (Karmarkar et al., 2004). However the reported prevalence in Indian studies are lesser compared with data from North
America and Europe where it accounts for $30 \%$ of the enterococcal infections, with most VRE isolates being $E$. faecium $(>90 \%)$ (Mathai et al., 2009).

In this study, E. faecium was the predominant species. Similar was the results obtained in studies from north India and south India (Karmarkar et al., 2004; Jain et al., 2011; Telkar et al., 2012).

As these infections can lead to severe mortality and morbidity, steps should be taken to prevent the spread of these infections by adopting stringent infection control measures.

Table.1 Speciation of enterococci based on sugar fermentation tests

\begin{tabular}{|c|c|c|c|c|c|c|c|}
\hline Species & Raffinose & Arabinose & Lactose & Sorbitol & Sucrose & Dextrose & Mannitol \\
\hline $\begin{array}{l}\text { E.faecium } \\
(73 \%)\end{array}$ & + ve & + ve & $+\mathrm{ve}$ & + ve & + ve & $+v e$ & +ve \\
\hline $\begin{array}{l}\text { E.faecalis } \\
(24 \%)\end{array}$ & -ve & -ve & $+\mathrm{ve}$ & -ve & $+\mathrm{ve}$ & $+\mathrm{ve}$ & $+\mathrm{ve}$ \\
\hline $\begin{array}{l}\text { E.durans } \\
(3 \%)\end{array}$ & -ve & -ve & -ve & $+\mathrm{ve}$ & -ve & $+\mathrm{ve}$ & -ve \\
\hline
\end{tabular}

Table.2 Specimen wise distribution of Enterococci

\begin{tabular}{|l|c|c|c|c|}
\hline $\begin{array}{l}\text { Specimen } \\
\text { processed }\end{array}$ & $\begin{array}{l}\text { No of } \\
\text { enterococal } \\
\text { isolates }\end{array}$ & E. faecium & E. faecalis & E. durans \\
\hline Stool & 52 & $39(75 \%)$ & $13(25 \%)$ & \\
\hline Pus aspirate & 23 & $16(69.7 \%)$ & $6(26 \%)$ & $1(4.3 \%)$ \\
\hline Urine & 15 & $8(53.4 \%)$ & $5(33.3 \%)$ & $2(13.3 \%)$ \\
\hline Throat swab & 7 & $7(100 \%)$ & & \\
\hline Blood & 3 & $3(100 \%)$ & & \\
\hline Total isolates & $\mathbf{1 0 0}$ & $\mathbf{7 3 ( 7 3 \% )}$ & $\mathbf{2 4}(\mathbf{2 4 \% )}$ & $\mathbf{3 ( 3 \% )}$ \\
\hline
\end{tabular}


Table.3 Antibiotic resistance pattern of enterococci

\begin{tabular}{|l|c|}
\hline \multicolumn{1}{|c|}{ Antibiotic tested } & \% resistance \\
\hline Linezolid & 0 \\
\hline Tigecycline & 0 \\
\hline Nitrofurantoin & 18 \\
\hline Vancomycin & 18 \\
\hline Doxycycline & 26.3 \\
\hline Cefoperazone/Sulbactam & 40 \\
\hline Amikacin & 50 \\
\hline Meropenem & 53.8 \\
\hline Ampicillin & 54.2 \\
\hline Imipenem & 55.4 \\
\hline Piperacillin/Tazobactam & 56.6 \\
\hline Gentamicin-high level & 65.1 \\
\hline Ciprofloxacin & 75.3 \\
\hline Penicillin G & 85.5 \\
\hline Clindamycin & 95.2 \\
\hline Cefazolin & 100 \\
\hline Trimethoprim/Sulfamethoxazole & 100 \\
\hline
\end{tabular}

Table.4 MIC of vancomycin resistant enterococcal isolates

\begin{tabular}{|c|c|c|c|c|c|c|c|c|}
\hline Species & $\begin{array}{l}\hat{\theta} \\
8 \\
z\end{array}$ & 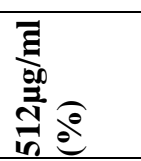 & 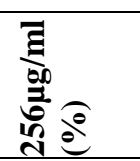 & 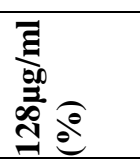 & 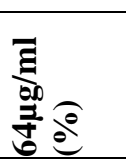 & 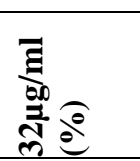 & 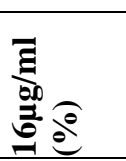 & 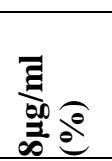 \\
\hline E.faecium & $9(50 \%)$ & 3 & 2 & 1 & 1 & 2 & 1 & 1 \\
\hline E.faecalis & $7(38.8 \%)$ & - & 3 & 4 & - & - & - & - \\
\hline E.durans & $2(11.1 \%)$ & - & 2 & - & - & & - & - \\
\hline Total & 18 & $\begin{array}{c}3 \\
(16.7 \%)\end{array}$ & $\begin{array}{c}7 \\
(38.8 \%)\end{array}$ & $\begin{array}{c}5 \\
(27.7 \%)\end{array}$ & $\begin{array}{c}1 \\
(5.5 \%)\end{array}$ & $\begin{array}{c}2 \\
(11.1 \%)\end{array}$ & $\begin{array}{c}1 \\
(5.6 \%)\end{array}$ & $\begin{array}{c}1 \\
(5.6 \%)\end{array}$ \\
\hline
\end{tabular}

Fig.1 Broth dilution method to determine vancomycin susceptibility showing an MIC of $256 \mu \mathrm{g} / \mathrm{ml}$.

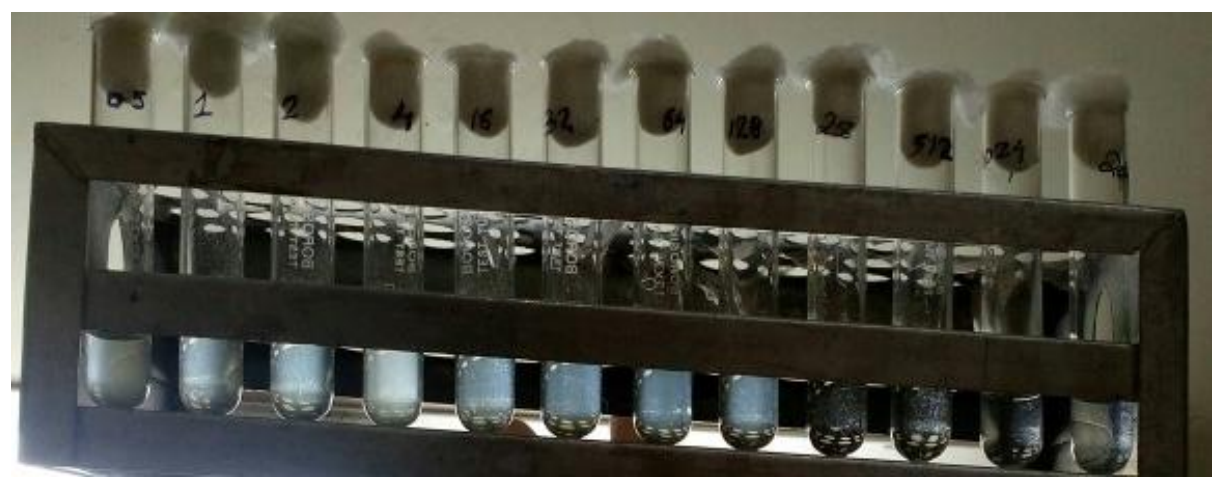


Various studies have shown the spread of VRE through the hand of health care professionals and contaminated environmental sources (Gilmore et al., 2014). Restricting the use of vancomycin and third-generations cephalosporins had shown some impact on VRE prevalence.

The association between clindamycin use and the prevalence of VRE suggests that restriction of this and perhaps other antianaerobic agents might be an important component of future antimicrobial interventions (Lautenbach et al., 2003).

Stringent infection control protocols, routine screening of environment as well as health care personnel, along with restricted use of vancomycin to prevent development of resistant strains may help to a certain extend to control the outbreaks of VRE in our setting where most people are immunocompromised and even mild infections can trigger severe sepsis and mortality.

Regarding empirical therapy, in treating patients with bacteremia, or severe infections, especially gastro intestinal and blood stream infections, one should keep in mind the high prevalence of vancomycin resistance and should include linezolid or tigecycline in their treatment protocol till sensitivity patterns are understood.

To conclude, large number of enterococcal isolates from cancer patients was resistant to vancomycin. All isolates were sensitive to linezolid and tigecycline. It is important to start therapy with linezolid or tigecycline in patients with severe enterococcal infections, pending susceptibility reports.

\section{References}

Agudelo Higuita, N.I., Huycke, M.M. 2014. Enterococcal Disease, Epidemiology and Implications for Treatment.. In: Gilmore MS, Clewell DB, Ike Y, et al., editors. Enterococci: From Commensals to Leading Causes of Drug Resistant Infection Boston: Massachusetts Eye and Ear Infirmary; 2014.

Facklam, R.R., M.D. Collins. 1989. Identification of Enterococcus species isolated from human infections by a conventional test scheme. J. Clin. Microbiol., 27(4): 731-734.

Jain, S., Kumar, A., Kashyap, B., Kaur, I.R. 2011. Clinico-epidemiological profile and high-level aminoglycoside resistance in enterococcal septicemia from a tertiary care hospital in east Delhi. Int. J. Appl. Basic Med. Res., 1: 80-83.

Karmarkar, M.G., Gershom, E.S., Mehta, P.R. 2004 Enterococcal infections with special reference to phenotypic characterization and drug resistance. Indian J. Med. Res., 119: 22-25.

Lautenbach, E., La Rosa, L., Marr, A., Nachamkin, I., Bilker, W., Fishman, N. 2003. Changes in the prevalence of Vancomycin-Resistant Enterococci in response to antimicrobial formulary interventions: Impact of progressive restrictions on use of vancomycin and third-generation cephalosporins. Clin. Infect. Dis., 36(4): 440-446.

Mandell, G., Douglas, R., Bennett, J., Dolin, R. 2005. Enteroocccus Species, Streptococcus bovis and Leuconostoc Species. In: Mandell, Douglas, and Bennett's principles and practice of infectious diseases. 6thed. New York: Elsevier/Churchill Livingstone; P.24112421.

Mathai, D., Biedenbach, D.J., Jones, R.N., Bell, J.M., Turnidge, J., Sader, H.S. 2009. Activity of daptomycin against gram-positive bacterial isolates from Indian medical centres (2006-2007). 
India Daptomycin Study Group. Int. J. Antimicrob. Agents, 34(5): 497-499.

Miller, W., Munita, J., Arias, C. 2014. Mechanisms of antibiotic resistance in enterococci. Expert Review of Antiinfective Therapy.,12(10): 1221-1236.

Praharaj, I., Sujatha, S., Parija, S.C. 2013. Phenotypic and genotypic characterization of vancomycin resistant Enterococcus isolates from clinical specimens. The Indian J. Med. Res., 138(4): 549-556.

Sreeja, S., Babu, P.R.S., Prathab, A.G. 2012. The prevalence and the characterization of the enterococcus species from various clinical samples in a tertiary care hospital. J. Clin. Diag. Res., 6(9): 1486-1488.
Telkar, A., et al. 2012. Change in the prevalence and the antibiotic resistance of the enterococcal species isolated from blood culture. J. Clin. Diag. Res., 6: 405-407.

Venditti, M., Tarasi, A., Comandini, U., Gentile, G., Girmenia, C., Micozzi, A. et al. 1993. Enterococcal septicemia in patients with hematological malignancies. European J. Clin. Microbiol. Infect. Dis., 12(4): 241-247.

Zaas, A.C.A.K., Song, X., Tucker, P., Perl, T.M. 2002. Risk Factors for Development of Vancomycin-Resistant Enterococcal Bloodstream Infection in Patients with Cancer Who Are Colonized with Vancomycin-Resistant Enterococci. Clin. Infect. Dis., 35(10): 1139-1146.

\section{How to cite this article:}

Swapna Raveendranath, Remya Nair and Sagila Savithri Gangadharan. 2017. Characterization and Antimicrobial Susceptibility Pattern of Clinical Isolates of Enterococci in a Tertiary Care Cancer Hospital, Kerala. Int.J.Curr.Microbiol.App.Sci. 6(2): 618-625.

doi: http://dx.doi.org/10.20546/ijcmas.2017.602.070 